\section{Analysis of Flower Color Variations at Different Developmental Stages in Two Honeysuckle (Lonicera Japonica Thunb.) Cultivars}

\author{
Jianjun Li ${ }^{1}$, Xiaoya Lian, Chenglin Ye, and Lan Wang \\ Green Medicine Biotechnology Henan Engineering Laboratory, Engineering \\ Technology Research Center of Nursing and Utilization of Genuine Chinese \\ Crude Drugs in Henan Province, College of Life Science, Henan Normal \\ University, Xinxiang 453007, China
}

Additional index words. period, pigment, carotenoid, chlorophyll, flavonoid the resource garden of the College of Life Sciences, Henan Normal University.

Determination of chloroplast pigment. Temporary slides were prepared for the observation of pigments from the plant material. A spectrophotometer was used to determine chlorophyll a, chlorophyll $\mathrm{b}$, and carotenoid content according to the wavelengths of their maximum absorption peaks, which were 665,649 , and $470 \mathrm{~nm}$, respectively. Determination of the three pigment contents was performed according to the following (Ren et al., 2015):

1. One gram of fresh corolla in each developmental stage was cut into pieces and put into a mortar. A small amount of quartz sand and calcium carbonate powder were added, and the mixture was ground into a homogenate with 2 to $3 \mathrm{~mL} 95 \%$ ethanol and treated for $10 \mathrm{~min}$ in the dark.

2. The extract was transferred into a $25-\mathrm{mL}$ volumetric flask with $95 \%$ ethanol.

3. The pigment ethanol extract with a light diameter of $1 \mathrm{~cm}$ and $95 \%$ ethanol as a blank control were injected into the same colorimetric cup. Absorbance measurements at wavelengths of 665 , 649 , and $470 \mathrm{~nm}$ were repeated three times. The following formulas were used for analysis:

$$
\begin{aligned}
& \text { Concentration of chlorophyll a: Ca } \\
& \quad=13.95 \mathrm{~A}_{665}-6.88 \mathrm{~A}_{649}
\end{aligned}
$$

Concentration of chlorophyll $\mathrm{b}: \mathrm{Cb}$

$$
=24.96 \mathrm{~A}_{649}-7.32 \mathrm{~A}_{665} \text {; }
$$

Concentration of chlorophyll: $\mathrm{Ca}+\mathrm{Cb}$;

$$
\text { Content of chlorophyll }=\frac{C \times V}{M},
$$

where $C$ is the chlorophyll concentration, $V$ is the constant volume (measured in milliliters) of chlorophyll extraction solution, and $M$ is the bud weight (measured in grams);

$$
\begin{aligned}
& \text { Concentration of carotenoid } \\
& =\frac{1000 \mathrm{~A}_{470}-2.05 \mathrm{Ca}-114.8 \mathrm{Cb}}{245} ; \\
& \text { Content of carotenoid }=\frac{C \times V}{M} .
\end{aligned}
$$

Determination of flavonoids in pigments was performed according to the following (Fu et al., 2013):

In this study, the distribution and content variation of pigments in two varieties of $L$. japonica Thunb. were studied. The results provide a basis for the identification and breeding of new varieties, and lay a foundation for the further study of pigment function and molecular mechanisms in honeysuckle.

\section{Materials and Methods}

Special subsidies were provided from the Public Health Services of Traditional Chinese Medicine in 2017 [(2017)66] and Henan Province Enterprise Technology Innovation Guidance Special Project (172107000031).

${ }^{1}$ Corresponding author. E-mail: 043081@htu.cn.
Plant material. The fresh flower buds or flowers of 'Damaohua' and 'Yujin 2' at six developmental stages were collected from
1. Seven stages of flowering buds were collected and placed in at $-80^{\circ} \mathrm{C}$, frozen for $24 \mathrm{~h}$, then processed by a vacuum freeze-drying machine for $72 \mathrm{~h}$, milled into powder, and finally placed in a dry, dark location until further analysis.

2. To prepare the methanol extract, $1.0 \mathrm{~g}$ of the freeze-dried powder was added to 10 $\mathrm{mL}$ methanol extraction solution. Ultrasonic extraction $(20 \mathrm{~Hz}, 3 \mathrm{~h})$ was carried out, followed by rotary evaporation with 
$10 \mathrm{~mL}$ methanol until a constant volume was obtained. Samples were stored at $4{ }^{\circ} \mathrm{C}$.

3. A standard solution of rutin $\left(2 \mathrm{mg} \cdot \mathrm{mL}^{-1}\right)$ was obtained by accurately weighing and dissolving $20 \mathrm{mg}$ rutin (constant weight) in a $10-\mathrm{mL}$ volumetric flask with ethanol to a constant concentration.

4. Standard samples of rutin with a concentration of $2 \mathrm{mg} \cdot \mathrm{mL}^{-1}$ were placed in a $10-\mathrm{mL}$ centrifuge tube at volumes of $0,0.2,0.4,0.6,0.8$, and $1.0 \mathrm{~mL}$. Then, $0.2 \mathrm{~mL} \mathrm{NaNO}_{2}$ was added at a concentration of $5 \%$ and was shaken for 6 min, followed by $0.2 \mathrm{~mL} 10 \% \mathrm{Al}\left(\mathrm{NO}_{3}\right)_{3}$, which was also and shaken and set for 6 min. Next, $1 \mathrm{~mL} \mathrm{4 \%} \mathrm{NaOH}$ was added, shaken well, and set for $15 \mathrm{~min}$ at room temperature; and a $60 \%$ ethanol solution was added to a constant volume of 10 $\mathrm{mL}$. The first solution was used as a blank, the absorbance value at a wavelength of $510 \mathrm{~nm}$ was measured, the absorbance $(X)$ was used to regress the concentration $(Y)$, and the standard curve was constructed.

5. Then, $0.1 \mathrm{~mL}$ methanol extract from each flower developmental stage was extracted to replace the standard product for analysis. This was repeated three times to obtain an average value.

6. The linear regression equation for the standard concentration of rutin $Y$ $\left(\mathrm{mg} \cdot \mathrm{mL}^{-1}\right.$ ) and absorbance $X$ was obtained in step 3, and the flavonoid content in the flower buds of honeysuckle at different developmental stages was calculated according to the following regression equation:

\section{Content of flavonoid}

(measured in milligrams per gram)

$$
=\frac{10 \times Y \times V}{M \times 0.1},
$$

where $Y$ is the concentration of flavonoids in the sample solution (measured in milligrams per milliliter), $M$ is the dry weight of the sample (measured in grams), $V$ is the final volume (measured in milliliters) of the sample, 0.1 is the amount of extract (measured in milliliters) added at the time of determination, and 10 is the constant volume (measured in milliliters) of the extract at the time of determination.

Determination of flower color. The buds or flowers of the young stage, three green period, two white period, great white period, silver period, and golden period of two cultivars were collected at $8 \mathrm{Am}$ and stored at $4{ }^{\circ} \mathrm{C}$. We used the RHSCC to determine the color of the corolla, and measurements were repeated five times. A colorimeter was used to determine $\mathrm{L}^{*}, \mathrm{a}^{*}$, and $\mathrm{b}^{*}$ (Yang et al., 2015). $\mathrm{L}^{*}$ represents brightness; a greater value of $\mathrm{L}^{*}$ indicates a brighter intensity. The value of $\mathrm{a}^{*}$ represents the difference between red and green. With a greater value of $a^{*}$, the color red is darker; with a smaller value of $a^{*}$, the color green is darker. $b^{*}$ is the difference between yellow and blue. With a greater value of $b^{*}$, the color yellow is darker; with a smaller value of $b^{*}$, the color blue is darker.

The outside corolla color was determined by measuring directly the upper half of the bud during the first four stages, then measuring the upper petals during the silver period and the golden period. The inside corolla color was determined by sticking the unfolded corollas of the first four stages onto slides with double-sided tape and measuring the upper petals with a colorimeter during the silver and golden periods.

SPSS (version 19.0, IBM) was used for data processing. Duncan's method was used for multiple comparisons of means.

\section{Results}

Variation and distribution of color and pigment between 'Damaohua' and 'Yujin 2'. The color during the young period was green, but faded in the two white period in 'Damaohua'. The great white period and silver period presented rice-white flowers; by the golden period, they had turned yellow (Fig. 1). The upper half of the flower bud during the young period was purple-red. The whole flower bud from the three green period to the great white period was red, but gradually became lighter; whereas during the silver period, the outer part was red and the inner part was white. During the golden period, the outer part was red and the inner part was white in 'Damaohua', but it was yellow in 'Yujin 2' (Fig. 1).

As shown in Fig. 2, the color of the corolla cross-section changed from dark green to yellow. From the young period to the two white period, the color changed from dark green to light green, then lightened to white during the great white period. From the silver period to the golden period, the color changed from light yellow to yellow. In 'Yujin 2', the pigment was distributed mainly in the upper epidermis and the head of the glandular hair cells. The cross-section of the corolla changed from green to yellow gradually, and the red pigment in the corolla epidermis changed gradually to yellow. The colors of each period in the two cultivars are shown in Fig. 1 and correspond to the $\mathrm{L}^{*}, \mathrm{a}^{*}$, and $b^{*}$ values in Table 1 . The $L^{*}$ value increased first and then declined, reaching its maximum value during the silver period then slightly declining during the golden period in both cultivars. The results were in line with the color of the silver period being the least intense among the six stages. In other words, as a* increased, the color faded. The $b^{*}$ value increased first, then decreased, reaching its greatest value during the golden period. The results were consistent with the color during the great white period, which was lightest during the golden period, and the corolla was yellow (Table 1).

The corolla cross-section was transparent except for nonglandular hairs at different developmental stages in 'Damaohua' and 'Yujin 2'. During the entire developmental

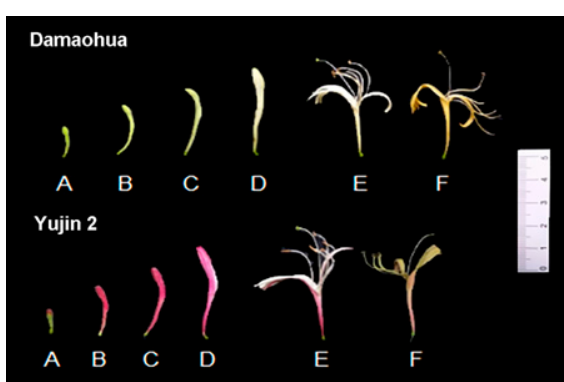

Fig. 1. The morphology of flowers at different developmental stages in two Lonicera japonica cultivars. (A) Young period. (B) Three green period. (C) Two white period. (D) Great white period. (E) Silver period. (F) Golden period.

period, the apexes of the glandular hairs changed from green to yellow in 'Damaohua'. The apexes of glandular hairs in 'Yujin 2' changed from red to yellow. The color variations of glandular hairs were concordant with the cross-sections of the corolla. The color variations are matched with the variation trends of $\mathrm{L}^{*}, \mathrm{a}^{*}$, and $\mathrm{b}^{*}$ values in Table 2 . From the young period to the golden period, the $\mathrm{L}^{*}$ value first increased and then decreased, reaching its maximum value during the silver period in two cultivars. From the young period to the golden period, the value showed an upward trend, which was consistent with the color fading in 'Damaohua'. The $\mathrm{a}^{*}$ value in 'Yujin 2' went through an updown-up process, and the greatest value appeared during the three green period, when the color was deep red. The $\mathrm{a}^{*}$ value of the outside of the corolla was greater in 'Yujin 2' than in 'Damaohua' in six stages. The color variations are shown in Figs. 1 and 2.

Chlorophyll, carotenoid, and flavonoid content. The chlorophyll content in the corolla of both cultivars showed a decreasing trend with different rates. The chlorophyll content declined rapidly from the young period to the two white period, and changed gradually from the two white period to the golden period (Fig. 3A). However, the content of carotenoids declined slightly from the young period to the silver period and rose sharply during the golden period (Fig. 3B).

The total flavonoid content was calculated by the linear regression equation of rutin, which was produced using the standard curve $Y=$ $12.95 X-0.0287, R^{2}=0.999$. The flavonoid content of 'Damaohua' and 'Yujin 2' showed a decreasing trend, with values of 128.61 and $188.19 \mathrm{mg} \cdot \mathrm{g}^{-1}$ during the young period, and 87.87 and $126.03 \mathrm{mg} \cdot \mathrm{g}^{-1}$ during the golden period, respectively (Fig. 3C). The flower of 'Yujin 2' was red because the carotenoid and flavonoid contents were greater than those of 'Damaohua' at all developmental stages.

\section{Discussion}

Effect of pigment distribution on flower color. Microscopy, spectrophotometry, colorimetry, and the RHSCC were used to compare and analyze pigment distribution, content, and color variations in the two L. japonica Thunb. cultivars at different developmental 


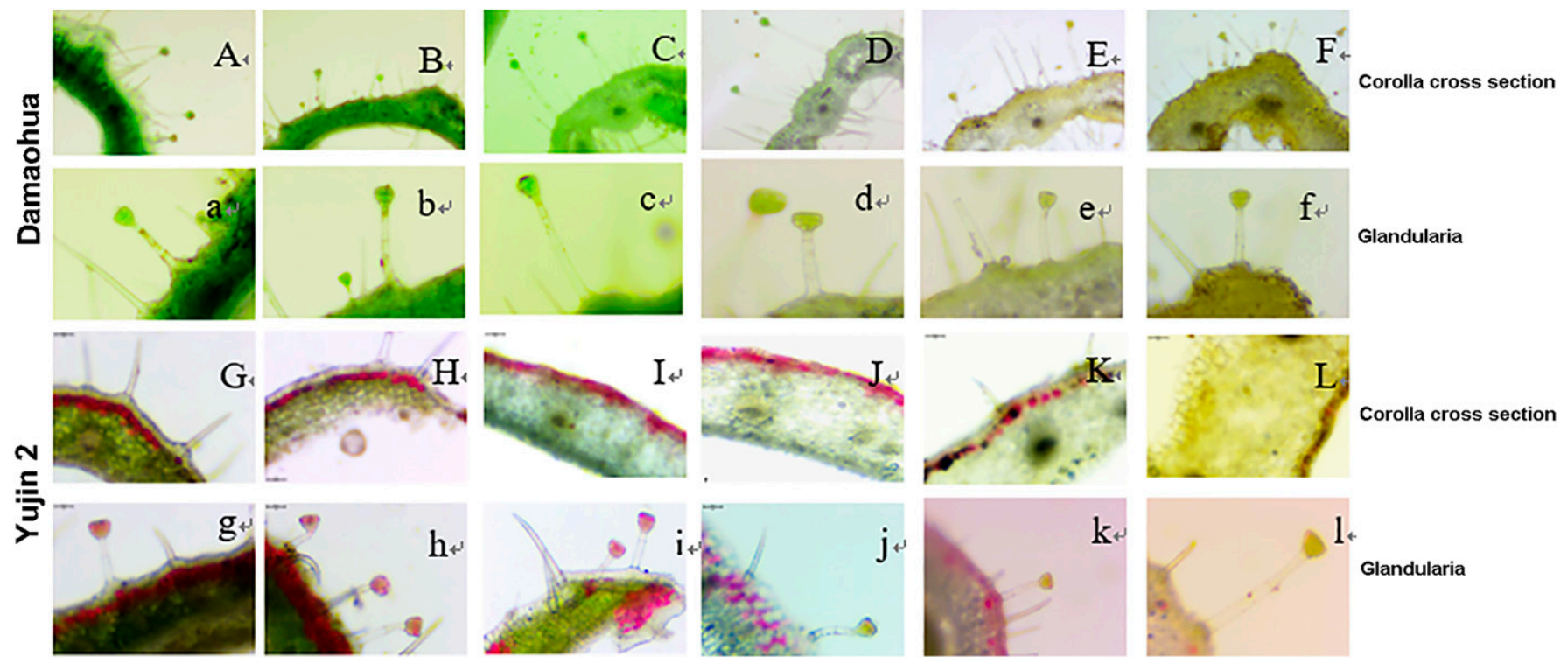

Fig. 2. The morphology of corolla cross-sections and glandularia during the six developmental stages in two Lonicera japonica cultivars. The morphology of corolla cross-sections during the six developmental stages of 'Damaohua': (A) Young period. (B) Three green period. (C) Two white period. (D) Great white period. (E) Silver period. (F) Golden period. The morphology of glandularia during the six developmental stages of 'Damaohua': (a) Young period. (b) Three green period. (c) Two white period. (d) Great white period. (e) Silver period. (f) Golden period. The morphology of corolla cross-sections during the six developmental stages of 'Yujin 2': (G) Young period. (H) Three green period. (I) Two white period. (J) Great white period. (K) Silver period. (L) Golden period. The morphology of glandularia during the six developmental stages of 'Yujin 2': (g) Young period. (h) Three green period. (i) Two white period. (j) Great white period. (k) Silver period. (l) Golden period.

Table 1. Variations in flower color inside the corolla during the six developmental stages of 'Damaohua' and 'Yujin 2'.

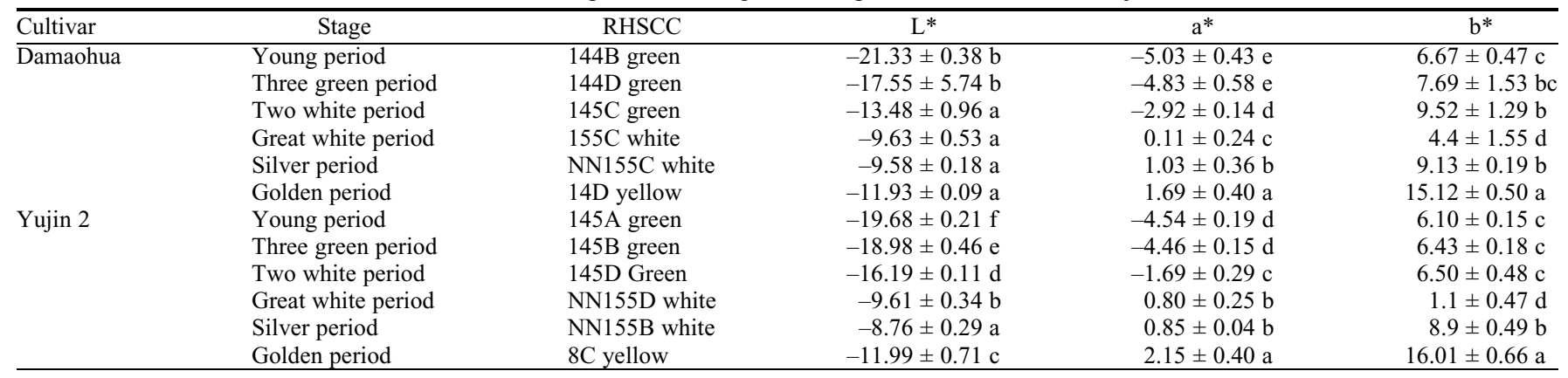

The different lowercase letters after the same cultivar represent significant differences at $P=0.05$ by Duncan's test $(\mathrm{n}=3)$.

RHSCC $=$ Royal Horticulture Society of Colorimetric Card; L* = lightness; $a^{*}=$ redness; $b^{*}=$ yellowness.

stages. There were great differences in corolla color and cross-section color between the different developmental stages and different varieties. One major reason for the variation in flower color is the distribution of the pigments. Yu (2013) reported that the anthocyanin content in the epidermal cells of this variety was quite high from the young bud period to the three green period. When the flower opens, anthocyanins gradually degrade, the red color of the upper epidermal cells decreases, and the yellow color of flavonoid pigments in the palisade tissue and the lower epidermal cells begin to appear, resulting in a yellow color ( $\mathrm{Yu}, 2013)$. The other reason for the fading of the flower color is that the corolla area expands faster than pigments can be synthesized, which results in a decrease in pigment content per unit area of corolla and, thus, fading of flower color (Zhong et al., 2012).

Effect of flower color on pigment content. The color of plants is codetermined mainly by the different distributions of chlorophyll, carotenoid, flavonoid, and betaine, which exist in the cytoplasm or vacuoles of plants. These compounds present different colors by reflecting sunlight. Carotenoids affect primarily the formation of yellow, orange, and red; flavonoids affect the formation of red, pink, purple, and blue colors in plants (Lee and Gould, 2002; Williams and Grayer, 2004). The constituents of the pigments were always chlorophyll and carotenoids in the developmental process of the two cultivars, but variation existed in the flower color because the content of each pigment changed during the growth process. The chlorophyll content was greater in the young period to three green period than in the other periods (Fig. 3). Moreover, it was not pure white but off-white in the great white period (Fig. 1), because there was a small amount of carotenoids during this stage. From the silver to golden periods, the color changed from offwhite to yellow. During this process, the content of flavonoids declines throughout the developmental stage of the flower. Therefore, flavonoids may play an auxiliary role in the yellow formation of golden flowers, although it is not the main reason why honeysuckle changes from white to golden flowers. The rapid increase in carotenoid content was the main reason for the change in flower color to yellow during the golden stage. The carotenoid content was $\approx 10$ times that during the silver period, whereas the chlorophyll content declined to the lowest amount, and the ratio of carotenoids to chlorophyll peaked (Fig. 3C). The carotenoids and total flavonoids in the 'Yujin 2' flower were greater than those in the 'Damaohua' flower from the young bud stage to the golden flower stage, which was why the 'Yujin 2' flower was red. The content of carotenoids in the golden period was $\approx 10$ times greater than that in the silver period, and the transition from the silver to the golden periods only took 2 to $3 \mathrm{~d}$. The sharp 
Table 2. Variations in flower color outside the corolla during the six developmental stages of 'Damaohua' and 'Yujin 2'.

\begin{tabular}{|c|c|c|c|c|c|}
\hline Cultivar & Stage & RHSCC & $\mathrm{L}^{*}$ & $a^{*}$ & $\mathrm{~b}^{*}$ \\
\hline \multirow[t]{4}{*}{ Damaohua } & Young period & $144 \mathrm{C}$ green & $-2.52 \pm 0.48 \mathrm{e}$ & $-6.32 \pm 0.31 \mathrm{e}$ & $6.89 \pm 1.24 \mathrm{e}$ \\
\hline & Two white period & $150 \mathrm{C}$ green & $-11.93 \pm 0.38 \mathrm{c}$ & $-3.72 \pm 0.51 \mathrm{c}$ & $12.55 \pm 0.02 b$ \\
\hline & Great white period & $155 \mathrm{~B}$ white & $-10.41 \pm 0.05 \mathrm{~b}$ & $-1.19 \pm 0.06 \mathrm{~b}$ & $8.49 \pm 0.77 \mathrm{c}$ \\
\hline & Golden period & $11 \mathrm{~A}$ yellow & $-12.07 \pm 0.31 \mathrm{c}$ & $3.68 \pm 0.52 \mathrm{a}$ & $14.05 \pm 0.74 \mathrm{a}$ \\
\hline \multirow[t]{4}{*}{ Yujin 2} & Young period & $71 \mathrm{~B}$ red & $-23.18 \pm 1.02 \mathrm{e}$ & $1.01 \pm 0.54 \mathrm{~b}$ & $4.18 \pm 1.38 \mathrm{c}$ \\
\hline & Three green period & $72 \mathrm{C}$ red & $-21.87 \pm 0.88 \mathrm{~d}$ & $5.36 \pm 5.57 \mathrm{c}$ & $7.46 \pm 0.55 \mathrm{~b}$ \\
\hline & Silver period & $73 \mathrm{C}$ light red & $-10.79 \pm 0.49 \mathrm{a}$ & $2.07 \pm 0.12 \mathrm{ab}$ & $5.57 \pm 0.66 \mathrm{c}$ \\
\hline & Golden period & 10B yellow & $-13.29 \pm 0.08 \mathrm{~b}$ & $3.83 \pm 0.66 \mathrm{a}$ & $11.91 \pm 1.37 \mathrm{a}$ \\
\hline
\end{tabular}

The different lowercase letters after the same cultivar represent significant differences at $P=0.05$ by Duncan's test $(\mathrm{n}=3)$.

RHSCC $=$ Royal Horticulture Society of Colorimetric Card; $L^{*}=$ lightness; $a^{*}=$ redness; $b^{*}=$ yellowness.
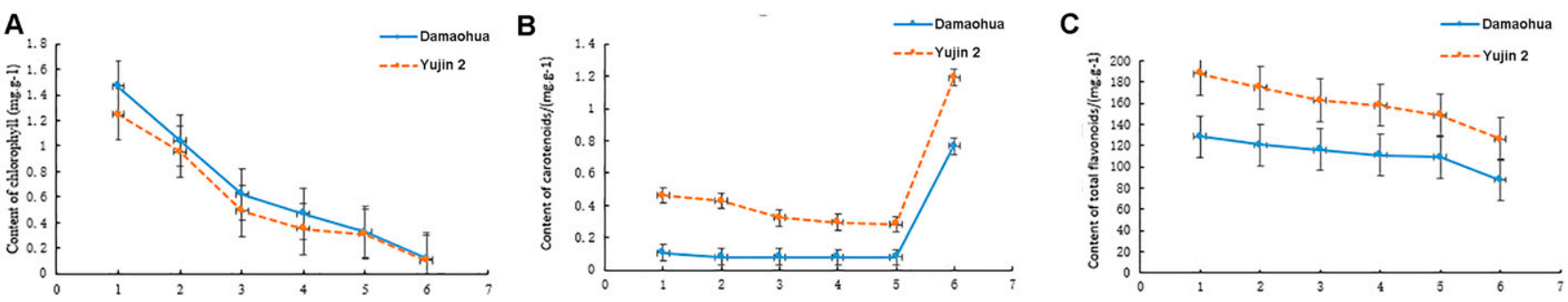

Fig. 3. (A) Chlorophyll content in flowers or buds, (B) carotenoid content, and (C) total flavonoid content in 'Damaohua' and 'Yujin 2'. The x-axis represents the six developmental stages of flowers; 1 , young period; 2 , three green period; 3 , two white period; 4 , great white period; 5 , silver period; 6 , golden period.

increase in carotenoid content over a short period of time was the main reason for the color change from white to yellow.

The corolla is purple in 'Yujin 2' because of abundant anthocyanins (Yu, 2013), which have very important physiologic roles, such as resisting oxidation, reducing blood fat, preventing tumors, preventing allergies, protecting gastric mucosa, and lowering blood sugar levels (Lv, 2001). Anthocyanins from the two L. japonica Thunb. cultivars, as natural edible pigments and functional food ingredients, have broad application prospects. Luteolin is a flavonoid that is highly expressed in 'Yujin 2' (Tan et al., 2018; Zhang et al., 2014). This result was consistent with the total flavonoid content of 'Yujin 2' presenting at a higher level than that of 'Damaohua' in this experiment. There are a variety of designs and colors in 'Yujin 2' that have a high ornamental value and may play an important role in landscaping (Liu et al., 2015). It is very important to regulate anthocyanin synthesis in honeysuckle breeding. With respect to molecular breeding, finding the key genes for anthocyanin synthesis will allow the overexpression or knockout of these genes to alter the color (Ling and Guo, 2009).

\section{Conclusion}

There were significant differences in corolla color, cross-section color, and the content of the three pigments between the two varieties of honeysuckle. Distribution and variation of pigments were the key factors affecting the flower color of honeysuckle. Our study provided a basis for the identifica- tion and breeding of honeysuckle varieties, and laid a foundation for further study on the function and molecular mechanisms of pigments.

\section{Literature Cited}

Fu, L.J., H.H. Li, L. Li, H. Yu, and L.Q. Wang. 2013. Analysis of the causes of flower color change of honeysuckle. Scientia Sci. 49(10): 155-161. [in Chinese].

He, S.Q., Q.F. Hu, and G.Y. Yang. 2011. Research status of honeysuckle of honeysuckle family. ORALCAREINDUSTRY 21(1):3033. [in Chinese].

Lee, D.W. and K.S. Gould. 2002. Why leaves turn red: Pigments called anthocyanins probably protect leaves from light damage by direct shielding and by scavenging free radicals. Amer. Sci. 90(6):524-531.

Ling, W.H. and H.H. Guo. 2009. Plant anthocyanins, p. 26-37. Science Press, Beijing. [in Chinese].

Liu, A.C., Q. Yan, Q. Wang, L.S. Wang, and C.M. Pang. 2015. Changes in the composition and content of anthocyanins during the flowering of Lonicera japonica L. J. Northwest A\&F Univ. (Natural Science Edition) 43(10):169-174. [in Chinese].

Lv, X.L. 2001. Antioxidant physiological activity of anthocyanin pigments and prospects for technical feasibility. China Food Additives Production and Application Industry Association. 2001 Asian Food Ingredients (China) Exhibition, 5th China International Food Additives Exhibition and the 11th National Food Additives Production and Application Technology Exhibition Academic Exchange Papers [C]. China Food Additives Production and Application Industry Association: China Food Additives Production and Application Industry Association, 4. [in Chinese].

Ren, Y.F., Y.P. Ma, and W.L. Wang. 2015. Study on the species and content of honeysuckle flower pigment. J. Anhui Agr. Sci. 43(02):9093. [in Chinese].

Shang, X., H. Pan, M. Li, X. Miao, and H. Ding. 2011. Lonicera japonica Thunb.: Ethnopharmacology, phytochemistry and pharmacology of an important traditional Chinese medicine. J. Ethnopharmacol. 138:1-21.

Tan, Z. W., W. Xia, Y. L. Yu, H.Q. Yang, L.J. Xu, W. Dong, H.L. Lu, F. Qu, and H.Z. Liang. 2018. Research progress in chemical constituents and pharmacology of honeysuckle. J. Anhui Agr. Sci. 46(09):26-28. [in Chinese].

Williams, C.A. and R.J. Grayer. 2004. Anthocyanins and other flavonoids. Nat. Prod. Rep. 21(4):539-573.

Yang, Q., T. Yuan, and X.B. Sun. 2015. Study on the color change of two peony varieties during flowering. J. Hort. 42(05):930-938. [in Chinese].

Yu, X.D. 2013. Preliminary study on the flowering pigment of Lonicera japonica L. and its formation mechanism. Wuhan University of Light Industry. [in Chinese].

Zhang, C., G. Chen, and Y.H. Li. 2012. The physiological and biochemical mechanism of flower color change during the flowering process of Qiaoyulan. Northwest Plant J. 32(4): 716-721. [in Chinese].

Zhang, X.N., J. Tong, Y.J. Zhou, and X.Y. Xu. 2014. Research progress on pharmacodynamic components and pharmacological effects of Lonicera edulis. Zhongguo Yaolixue Tongbao 30(08): 1049-1054. [in Chinese]

Zhong, P.X., L.S. Wang, S.S. Li, Y.J. Xu, and M.L. Zhu. 2012. Changes in flower color and pigmentation during the flowering process of peony. J. Hort. 39(11):2271-2282. [in Chinese].

Zhu, M.L., L.S. Wang, H.J. Zhang, Y.J. Xu, X.C. Zheng, and L.J. Wang. 2012. Composition of anthocyanin in cold-tolerant lotus petals and its relationship with flower color. Acta Bot. Sin. 47(5):437-453. [in Chinese]. 